\title{
CHARACTERIZING THE ENGINEERING EDUCATION GRADUATE STUDENT EXPERIENCE IN CANADA: DESCRIPTIVES
}

\author{
Patricia Sheridan $^{a *}$, Jillian Seniuk Cicek ${ }^{b}$, Liz Kuley ${ }^{c}$, and Robyn Mae Paul ${ }^{d}$ \\ ${ }^{\mathrm{a}}$ Faculty of Applied Science and Engineering, University of Toronto, ON, Canada; ${ }^{\mathrm{b}}$ Faculty of Engineering, University of

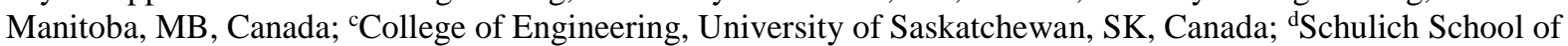 \\ Engineering, University of Calgary, AB, Canada \\ *patricia.sheridan@utoronto.ca
}

\begin{abstract}
Four Canadian Engineering Education graduate students from the Universities of Manitoba, Saskatchewan, Toronto, and Calgary are conducting a national mixed-methods research study to characterize the identity of graduate students studying engineering education in Canada. The first phase of this study comprised of the dissemination of a survey designed using McAlpine's Identity-Trajectory framework to explore whom our engineering education graduate students are, how our graduate studies are manifest in this field, and how our academic identities are formed through the construction of our unique intellectual, institutional, and networking experiences. This paper presents select findings and descriptive analyses from these survey data. Findings show that participants in our study predominantly identify as female, come from engineering backgrounds, are over-stretched in terms of commitments, need better access to research funding and peer communities, actively present at conferences, and are sufficiently supported by their institutions and supervisors to feel that they can conduct quality research in engineering education. Noteworthy, is that the gender demographic in our study participants, which is predominantly female, is in contrast to the minority female demographic found in engineering graduate studies. Significantly, findings suggest that graduate students pursuing degrees in engineering education may be guided by a potentially unconscious positivistic approach to their research.
\end{abstract}

Keywords: graduate students; engineering education; Canada; identity; program supports and constraints; survey data; descriptive analyses.

\section{INTRODUCTION}

Engineering education is an area of study in Canada that is developing into a discipline, with its own association, national annual conference, research publications, and development of graduate degree programs. There are many students working towards graduate degrees with a focus in engineering education, in a range of diverse capacities. This student community is in its nascent stages, with to date, little research conducted to determine what supports and infrastructure are necessary for members of this community to thrive as graduate students and as researchers.

To fill this gap, four Canadian Engineering Education graduate students from the Universities of Manitoba, Saskatchewan, Toronto, and Calgary are conducting a national mixed-methods study to characterize the identity of graduate students studying engineering education in Canada. The motivations and structure of this study, and the development of the Canadian Engineering Education Student Identity Study (CEESIS) survey were first presented at CEEA 2016 [1]. The survey was designed using McAlpine's Identity-Trajectory framework [2], [3], [4], [5] to guide to the construction of questions along three distinct areas of identity emergence: intellectual, institutional, and networking experiences. The objectives of this study are to explore who our engineering education graduate students are, how our graduate studies are manifest in this field, and how our academic identities are formed through the construction of our unique intellectual, institutional, and networking experiences. Our research objectives were conceived to benefit and influence three engineering education stakeholder groups: graduate students, faculty, and the Canadian agencies responsible for research funding.

This paper presents select findings from our survey data from the first phase of our research, with the aim of our greater study to provide engineering educators in Canada, and CEEA/ACEG at large, with an overview of the graduate students pursuing degrees related to engineering education in Canada, and some insight into the structure of their degrees, the development of their research, and the supports and constraints they are experiencing as they develop their identities as engineering education researchers.

\section{RESEARCH DESIGN AND METHODS}

Graduate students in Canada who identify as having engaged in, or engaging in engineering education research were contacted by our study team to complete an on-line survey about their experiences and the institutional structures that support or constrain them. This was the first 
step in our sequential explanatory study to understand how graduate students in engineering education research were experiencing their degrees and develop their identities as engineering education researchers. The survey contained approximately 40 questions of both qualitative and quantitative structure that were designed to investigate, but were not limited to: degree requirements and composition; institutional infrastructure and supports; the role of being an engineer; motivations to engage in engineering education research; and understandings of the similarities and differences between engineering and engineering education research.

We received ethics approval for our study from all four of our institutions, and disseminated our survey through multiple channels: CEEA/ACEG mailing lists; student contacts made at the CEEA 2015 Student Meet and Greet; institutional and academic contacts; and through snowball sampling (where students, faculty and CEEA/ACEG members were invited to pass the survey on to known graduate students engaging in engineering education research in Canada). The survey was open for three weeks in March 2017. Both Masters and PhD students were invited to complete the survey.

Findings presented in this paper demonstrate an overview of the quantitative data that the researchers considered would be most relevant and interesting to the CEEA/ACEG community. Thus, only preliminary, descriptive findings are presented here, with more nuanced explorations of the data intended for future publications. Topics from the survey selected for description in this paper include: background education, gender identity, geographic location of targeted population, degree requirements, funding situations, engineering skills transfer, licensure, and research framing. Data are provided entirely in descriptive form with no statistical analyses completed.

\section{DEMOGRAPHICS}

During the three weeks in which the survey was accessible, 37 individuals opened the survey, 29 started the survey, and 24 completed the survey. As participants dropped off at different points in the survey, or opted not to answer specific questions, the subset of participants who responded to each question is different. Participant numbers for each question analysed are articulated in specific findings.

Sixty-eight percent of participants who completed the survey identified as female, and $32 \%$ of participants identified as male. If this balance is indicative of the field of engineering education in Canada, this would be in sharp contrast to the Canadian engineering graduate school demographic, of which only $24 \%$ identify as female [6]. It would be noteworthy to explore if engineering education research is attracting more female students than male students, and thus a higher percentage of females than traditional engineering disciplines.

In terms of background education, $62 \%$ of students who identify as engaging in engineering education graduate research have an engineering background, $17 \%$ have a background in engineering and another discipline, and $21 \%$ have a background in a discipline other than engineering.

Of the students who have a background in engineering, the majority of students come from two areas: electrical and computer engineering, or mechanical engineering (see Fig. 1). Again, if these data are indicative of the field, rather than only of our study participants, it would be noteworthy that this predominantly female engineering education discipline is being generated by two of the engineering disciplines with the historically lowest female enrolment [6].

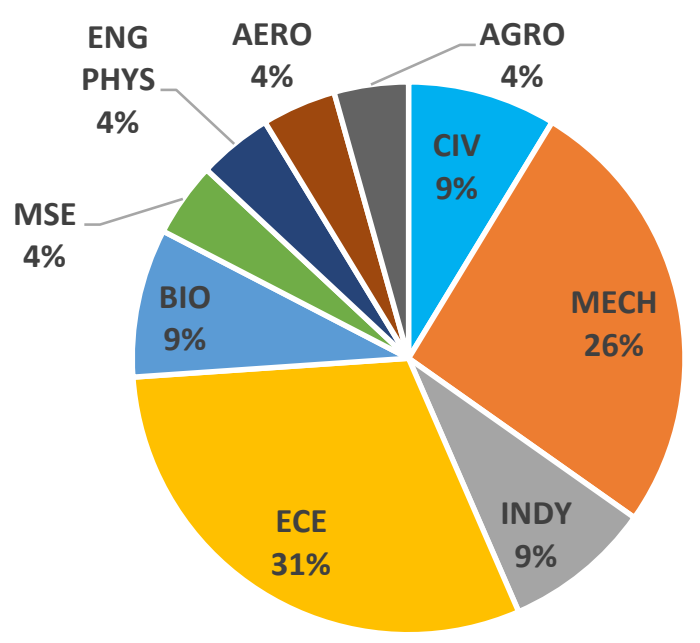

Fig. 1 Participants with engineering backgrounds $(n=23)$.

In terms of geographic location, students are engaging in engineering education research across the country, as demonstrated in Fig. 2.

Participants were occupied in a variety of ways before their graduate work in engineering education. The largest percentage of participants were full time students before beginning their studies. Twenty-one percent of students were working in the field of engineering before commencing their degrees (see Fig. 3).

The majority of engineering education students are members of at least two of the following associations: CEEA/ACEG, American Society for Engineering Education (ASEE), or the CDIO Initiative (Conceive Design Implement Operate.)

In addition to working towards their degrees, students in engineering education are simultaneously engaged in multiple projects and/or other jobs (see Table 1). The majority of participants are continually multi-tasking while trying to balance the requirements of their degrees and their research. All students who completed the survey present at 
conferences. This is a promising finding, as this is a small community, and this activity ensures that students have the opportunity to meet and build connections with others in the field.

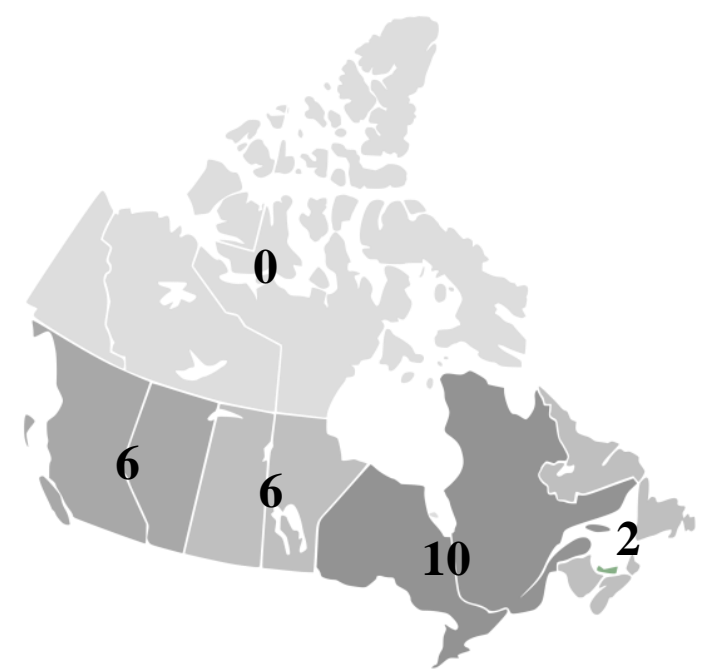

Fig. 2 Number of survey respondents by Canadian region $(n=24)$.

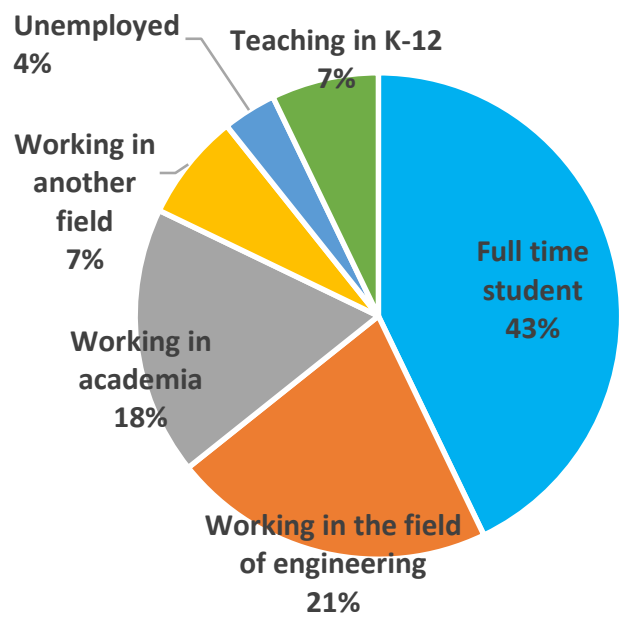

Fig. 3. Distribution of participants' occupations before beginning their studies in engineering education $(n=28)$.

\section{DEGREE COMPOSITION}

All participants reported that they were receiving a degree that had a name other than Engineering Education, with most degrees predominantly disciplinary engineering degrees (with the discipline being their supervisor's affiliation). Four students will not be receiving engineering degrees, instead receiving degrees in Education, English, or Interdisciplinary Studies.
The degree requirements participants have were fairly standard across the country. All reported a coursework component to their degree. Access to courses that were not in students' home departments were reported as both the hardest to access and the most relevant to their degrees. Students with an engineering background wanted greater access to educational theory and research methods courses. Students without an engineering background wanted greater access to engineering design, history, and philosophy of engineering courses, as well as a better understanding of engineering teaching practices.

Although the dataset covers both Masters and $\mathrm{PhD}$ students, degree requirements were fairly common across participants (albeit with different names for activities across different institutions). Aside from the thesis defence, the most common activity required of participants is a seminar course. These data provide no detailed information about the topics or content of the seminar courses; however, this information could be sought in the upcoming qualitative portion of this study (Phase 2).

Table 1: Student responsibilities in addition to degree requirements $(n=24)$

\begin{tabular}{lc}
\hline Activity & No. students \\
\hline Instructor & 14 \\
Teaching assistant & 19 \\
Research assistant & 11 \\
Supervising undergraduates & 5 \\
Involved in research projects aside & 17 \\
from thesis & 10 \\
$\begin{array}{l}\text { Publishing research in addition to } \\
\text { thesis }\end{array}$ & 24 \\
Presenting at conferences & 11 \\
Sitting on committees & 9 \\
Working full time/consulting & \\
\hline
\end{tabular}

Table 2: Degree requirements for students $(n=29)$

\begin{tabular}{lc}
\hline Activity & No. Students \\
\hline Seminar Course & 21 \\
Workshops & 2 \\
Thesis proposal & 17 \\
Research proposal & 14 \\
Candidacy exam & 15 \\
Annual progress reporting & 18 \\
Committee meetings & 16 \\
Regular supervisor meetings & 20 \\
Thesis defence & 28 \\
\hline
\end{tabular}




\section{DEGREE FUNDING}

Securing funding for a degree in engineering education was an area of concern discussed by nine participants. Degrees were funded in different ways by each university with a large portion of students $(46 \%)$ having to self-fund at least part of their degree (see Table 3).

Table 3: Participants' funding sources for engineering education degree - some had multiple sources $(n=24)$

\begin{tabular}{lc}
\hline Funding Source & No. Students \\
\hline Self-funded & 11 \\
Parents & 1 \\
Partner & 1 \\
Advisor/supervisor funding & 14 \\
Institution (obligated to fund) & 14 \\
Institution (not obligated to fund) & 4 \\
Scholarship - Provincial & 6 \\
Scholarship - Federal (SSHRC, NSERC) & 7 \\
Scholarship - Non-Government & 3 \\
Teaching assistantship & 14 \\
Research assistantship & 10 \\
Other & 6 \\
\hline
\end{tabular}

A larger percentage of participants were at a university that had an obligation to fund, which resulted in advisors/supervisors supporting their students. Interestingly, seven participants reported that they had funding from federal scholarships, such as SSHRC and NSERC. This number appeared high to the researchers based on their knowledge of the difficulty in receiving federal funding, particularly for engineering education, in Canada. Exploring the dataset further, it became evident that students who received funding from their institution's NSERC Design Chair reported this as an NSERC scholarship. Thus, this number is not reflective of students who actually obtained CGS-M or CGS-D scholarships for their research.

\section{TRAINING AND SUPPORT}

The respondents were divided 50/50 as to whether they agreed that they received adequate training to perform the research they were undertaking (see Fig. 4). The majority of respondents reported that they could have received better training in the areas that they did not have a background in (i.e., in engineering or education).

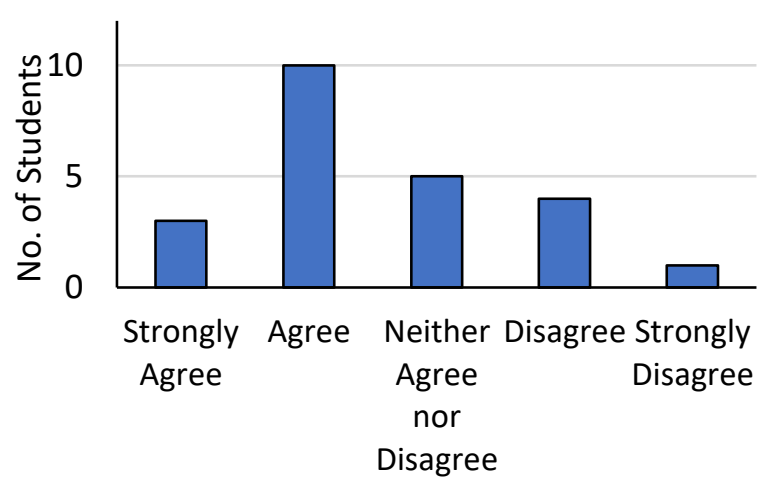

Fig. 4. Student agreement with the question: I am confident that I am receiving the appropriate training/education in order to conduct quality research in Engineering Education $(n=23)$.

Participants were also asked about their committee structure. For students who entered the program with an engineering background, 11 reported that they had a nonengineer on their committee, and seven reported they did not. In terms of committee expertise, having committee members who were very experienced in engineering education research was uncommon, and having committee members who were very experienced in engineering research was very common. Committee members' expertise in social science and education was lower than committees' engineering research experience, but more present than engineering education research expertise. Thus, student committees were most experienced in engineering research, but contained expertise in education and social sciences research as well.

\section{RESEARCH CONSIDERATIONS}

Students were asked to identify the types of research that they were conducting, and the ways in which they were thinking about their research. For those who had a background in engineering, there was strong agreement that the engineering design or systems thinking that they learned in their undergraduate programs was useful to their current research. Students reported these ways of thinking as much more relevant to their current degrees than their technical engineering knowledge (see Fig. 5).

In terms of methodologies, the majority of students reported conducting mixed methods study designs, with no students reporting that they were only using quantitative methods in their research. Four students, completing degrees both within and outside of engineering degree designations, reported using only qualitative research methods. 


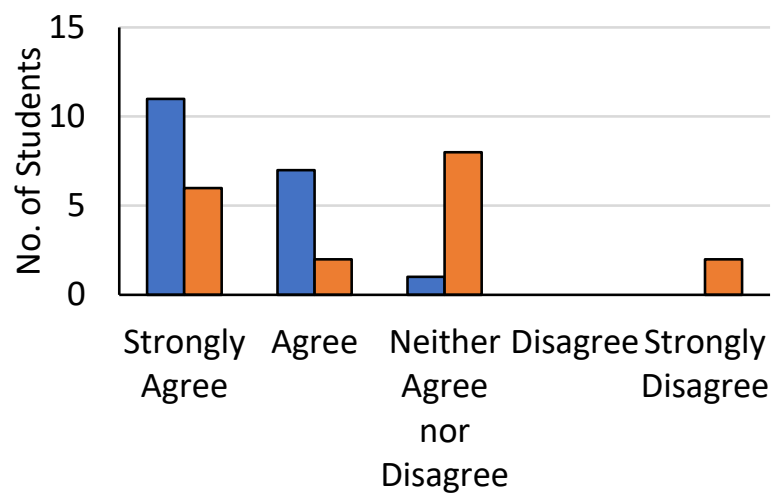

$\square$ Use engineering design/systems way of thinking $\square$ Use engineering knowledge

Fig. 5. Student agreement with statements about the use of engineering training in their current research $(n=19)$.

Students were additionally asked to report which of the three approaches in Table 4 they were using to frame and/or understand the research they were conducting. Twenty-five participants responded to this question. While a conceptual framework and theoretical grounding for the research were cited as approaches taken by more than half of participants' responses, there were few participants who reported considering the epistemology of their research. Students who typically considered epistemology, considered all three approaches.

Table 4: Student approaches to framing and/or understanding their research $(\mathrm{n}=25)$

\begin{tabular}{lc}
\hline Approach & $\begin{array}{c}\text { Total no. } \\
\text { Participants }\end{array}$ \\
\hline Conceptual Framework & 19 \\
Theoretical Framework & 19 \\
Epistemology & 8 \\
\hline All Three Approaches & 7 \\
\hline
\end{tabular}

These data are interesting to the researchers, as they are somewhat dissonant to the qualitative methodology that participants primarily reported employing. Given that all participants are conducting some qualitative research for their research, it is noteworthy that only $76 \%$ were situating their work within conceptual and/or theoretical frameworks. And it is surprising that only 32\% of participants were considering the epistemology inherent to their work. This may stem from the fact that the majority of students come from an engineering background, where the concept of epistemology is not explicit or traditionally discussed, and where a positivistic approach to knowing is historically taken. It may also be due to the supervisory committee structure, particularly if engineering researchers are the predominant supervisors, as they may be perpetuating a positivistic epistemological approach whether consciously or unconsciously - to their students' research. It would be worth exploring whether these data are suggestive that engineering education students who have a background in engineering ultimately bring a positivist perspective to their research. A positivistic approach, despite its potential incongruity with qualitative methodologies may be due to an unconscious and/or trained familiarity with approaching the world in this way, rather than a conscious consideration and choosing of an epistemology that is appropriate for the research. This is an area worth investigating.

\section{COMMUNITY CONCERNS}

Throughout the survey, five areas of concern emerged for students undertaking graduate degrees in engineering education: lack of lab/research group feedback; funding; engineering licensure; cooperation between Engineering and Education faculties; and clearer degree expectations.

\subsection{Lack of lab/research group feedback}

Ten participants commented that they did not have a lab group to commune with and from which to seek critical feedback, and they viewed this as a shortcoming in their program. Developing communities within their institutions to provide access to instantaneous peer feedback and guidance from other students in the field was important to participants, who wished to see this aspect developed. However, many students commented that there are not enough students in their university engaging in engineering education research to build such a group. The need for a peer community is an important finding in the data, and may be something that stakeholders in engineering education can work to achieve.

\subsection{Funding}

Nine students raised degree funding as an issue. The main theme in these comments was the inability to get scholarships given the interdisciplinary nature of the field, which didn't fit into the silos of tri-council scholarship applications. Participants commented that this limited the type of research that they could do. Additionally, the lack of funding required them to take up other work while completing their degrees in order to fund their education. These data draw attention to another area of concern, which has already been noted by Canadian stakeholders in engineering educators, who have appealed to the Fundamental Science Review Panel to address the gaps in STEM education funding [7]. 


\subsection{Engineering licensure}

Nine students with engineering backgrounds reported that getting their license was very important to them both personally, and to their future career paths. Three students reported having already attained professional licensure due to their work in industry before commencing with their engineering education degree. For those who did not report working in industry before their degree, there was substantial concern over their ability to get credit for their degree in order to receive their license through their provincial licensing bodies.

\subsection{Co-operation between Departments/Faculties}

Four students commented on the struggles they had getting access to resources in the departments/faculties in which their degree was not housed. Students discussed access barriers to courses relevant to their degrees/research and to interactions with experts in departments who could help them frame their research.

\subsection{Clearer degree expectations}

Two students commented that they struggled to understand their degree requirements and discussed having to meet multiple degree expectations due to an approach that inferred dual-disciplines rather than inter-disciplines (i.e., two disciplines as opposed to one discipline). There was a strong undertone expressed by these participants of not knowing exactly what was expected of them, or being overwhelmed by the multitude of expectations.

\section{DISCUSSION}

Two themes emerged from these analyses to which the researchers want to draw particular attention: gender demographics and epistemologies.

The gender identity breakdown of the engineering education graduate participants in this study is distinctly different from that of engineering graduate students. The study population predominantly identified as female, and the majority of those from an engineering background hail from two disciplines in engineering with the lowest female enrolment (i.e. electrical and computer engineering, and mechanical engineering). This leads us to question what is attracting these students to the field of engineering education. What in particular is motivating this demographic to pursue research in engineering education? If our sample population is representative of the population studying engineering education in Canada, what are the implications if those studying the field are not representative of the population within the field?

Another area of interest is that students who enter engineering education from an engineering background are applying their design thinking and hypothetically, their implicit positivistic engineering epistemology to their research. This may point to engineering education and engineering education research holding a distinct place from traditional education research. This may perhaps make engineering education research and its subsequent theories more relevant to application in the context of engineering undergraduate education and training. However, it may also mean that the research in the field is perpetuating blind spots in understandings and knowledge by not fully embracing the epistemologies underlying the methodologies of traditional education research/training. This is an area that we plan to investigate further.

\section{CONCLUSION}

This paper presents a preliminary understanding of the nascent community of engineering education graduate students in Canada. Participants in our survey predominantly identify as female, come from engineering backgrounds, are over-stretched in terms of commitments, need better access to research funding and peer communities, actively present at conferences, and are sufficiently supported by their institutions and supervisors to feel that they can conduct quality research in engineering education. If the majority female demographic of our survey respondents is indicative of the field of engineering education in Canada, this would be in sharp contrast to the Canadian engineering graduate school demographic, of which only a minority identify as female. Interestingly, the majority of our participants with engineering backgrounds come from electrical and computer engineering, or mechanical engineering - two of the engineering disciplines with the historically lowest female enrolment [6]. These trends in our survey data are worth further exploration. Also significant, is the suggestion that graduate students pursuing degrees in engineering education - especially graduate students who are engineers and/or who are supervised by engineers - may be guided by a positivistic approach to their research. If so, this may be something that separates engineering education research from traditional education research, and may be relevant to the transition of research into practice in the engineering classroom. On the other hand, it may bring into question the quality of engineering education research being conducted. This is an area that we will explore.

The objective of our larger study is that our findings will influence the growth of engineering education degree programs in Canada by identifying areas where our students both struggle and thrive. By stimulating dialogue around the happenings in this field as it emerges, we can increase our understandings and better nurture the specific needs of our fledgling graduate student community. These preliminary findings will be used to inform the further exploration of this population through the pursuit of extended interviews in the qualitative stage of our greater 
research study. Ultimately, with the support of these research findings, we aim to more effectively facilitate our Canadian graduate students' evolution into globally influential engineering education researchers.

\section{Acknowledgements}

The authors would like to thank members of the CEEA/ACEG and ASEE community who helped guide our thinking around the survey questions: Brian Frank, Jake Kaupp, Sean Maw, Susan McCahan, Julie Martin, Shanna Daly, and Marisa Orr. The researchers would also like to thank their supervisors who supported them in conducting this research, and the CEEA/ACEG community for allowing us to recruit participants through your network.

\section{References}

[1] J. Seniuk Cicek, L. Kuley, P. Sheridan and R. Paul, "Characterizing the Engineering Education Graduate Student Experience in Canada: Research Development \& Reflections," in Canadian Engineering Education Association Annual Conference, Halifax, NS, Canada, 2016.
[2] L. Thomas, "Identity-trajectory as a theoretical framework in engineering education research," in Proc. American Society for Engineering Education Annual Conference \& Exposition, Indianapolis, IN, 2014.

[3] A. Gardener and K. Willey, "Engineering academics' identity transitions in becoming established engineering education researchers," in Research in Engineering Education Symposium, Dublin, Ireland, 2015.

[4] L. McAlpine, "Identity-trajectories: Doctoral journeys from past to present to future," Australian Universities Review, vol. 54, no. 1, pp. 38-46, 2015.

[5] L. McAlpine, C. Amundsen and G. Turner, "Identitytrajectory - Reframing early career academic experience," British Education Research Journal, vol. 40, no. 6, pp. 952-969, 2014.

[6] Engineers Canada, "Canadian Engineers for Tomorrow Trends in Engineering Enrolment and Degrees Awarded 2010-2015," 2016. [Online]. Available: https://engineerscanada.ca/reports/canadian-engineers-fortomorrow\#trends-in-engineering-enrolment-and-degreesawarded-. [Accessed 1 May 2017].

[7] J. Seniuk Cicek, Personal Communication. 1 May 2017. 